\title{
La puesta en escena como rasgo de estilo en la poesía francesa
}

\author{
Antonio ANSÓN \\ Universidad de Zaragoza \\ Departamento de Filología Francesa \\ aanson@unizar.es
}

Recibido: 27/08/2014

Aceptado: 07/11/2014

\begin{abstract}
Resumen
En este trabajo estudiamos los orígenes de la puesta en escena poética como rasgo de estilo. Nos remontamos a sus orígenes en la poesía fonética de las vanguardias históricas, futurismo y dadaísmo, siguiendo el hilo de la historia a través de la poesía sonora y concreta, el letrismo, hasta llegar al rap, el spoken word y el slam. El estudio se centra en tres autores: Pierre Albert-Birot, Antonin Artaud y Gherasim Luca. La tesis propuesta consiste en la consideración de la realización vocal del poema como rasgo estilístico imprescindible para la comprensión de la materia poética que lo constituye.
\end{abstract}

Palabras clave: Pierre Albert-Birot, Antonin Artaud, Gherasim Luca, Poesía fonética, Poesía sonora, Puesta en escena, Spoken word. Slam.

\section{Les origines de la mise en scène comme élément de style dans la poésie}

\section{française}

\section{Résumé}

Ce travail analyse les origines de la mise en scène poétique comme trait de style. En amont nous avons fait des recherches du côté des avant-gardes, en particulier le futurisme et le dadaïsme. En aval nos travaux débouchent sur le Rap, le spoken Word et le slam, en passant par la poésie phonétique, ainsi que la poésie sonore et la poésie concrète. Notre travail étudie en particulier l’œuvre de Pierre AlbertBirot, Antonin Artaud et Gherasim Luca. La thèse proposée défend la réalisation vocale et sonore du poème comme élément inséparable de la matière poétique.

Mots clés: Pierre Albert-Birot, Antonin Artaud, Gherasim Luca, Poésie phonétique, Poésie sonore, Mise en scène, Spoken word. Slam.

\section{The Origins of 'Staging' as a Style Feature in French Poetry}

\begin{abstract}
In this study we examine the origins of poetic 'staging' as a feature of style, visiting its origins in the phonetic poetry of relevant avant-garde manifestations, such as Futurism and Dadaism. Its historical thread is followed through sonorous and concrete poetry-Letterism—until the advent of Rap, the Spoken Word and Slam. The study focuses on three authors: Pierre Albert-Birot, Antonin Artaud and
\end{abstract}


Gherasim Luca. Our thesis considers the vocal embodiment of the poem as an essential stylistic trait in the understanding of the constituent poetic matter.

Key words: Pierre Albert-Birot, Antonin Artaud, Gherasim Luca, Phonetic poetry, Sound poetry, Staging, Spoken Word, Slam.

Sumario: Introducción. 1. Claves históricas. 2. Primero fue la voz. 3. De la voz al grito. 3.1. El grito de Pierre Albert-Birot. 3.2. El grito de Antonin Artaud. 3.3. Del grito al balbuceo de Gherasim Luca. 4. A modo de conclusión.

\section{Referencia normalizada}

Ansón, A. (2015). «La puesta en escena como rasgo de estilo en la poesía francesa ». Thélème. Revista Complutense de Estudios Franceses, Vol. 30, Núm. 1: 9-23. http://dx.doi.org/10.5209/rev_THEL.2015.v30.n1.46497

\section{Introducción}

A comienzos del siglo XX comienza y se desarrolla una línea poética que se caracteriza por hacer de la interpretación un rasgo de estilo indisociable de la forma del poema. No se trata de un movimiento literario orgánico como pudo ser el surrealismo, o una corriente poética como el letrismo o la poesía concreta. Hacemos referencia a una cadena de poetas sin un nexo histórico, aunque beban de una tradición literaria. Comparten el hilo conductor de la voz como característica fundamental de su quehacer poético y la puesta en escena como la marca estilística que los identifica.

Los primeros eslabones de esta cadena corresponden a Pierre Albert-Birot, Antonin Artaud y Gherasim Luca. Los experimentos vanguardistas de los dos primeros, y la práctica personalísima e irrepetible de Luca, van a materializarse en una corriente contemporánea que forman un grupo de poetas de expresión francesa cuyo marchamo es precisamente la puesta en escena como rasgo que los identifica. Para entender su manera de hacer e interpretar la poesía hemos de buscar las fuentes en estos tres nombres claves que echan mano de la interpretación como rasgo de estilo. A este grupo de poetas de expresión francesa, herederos de Albert-Birot, Artaud y Luca, nacidos entre 1950 y 1960, pertenecen Christophe Tarkos, Julien Blaine, Christian Prigent, Serge Pey, Philippe Beck, Nathalie Quintane, Jean-Pierre Bobillot, Jean-Michel Espitallier, Charles Pennequin, Vincent Tholomé. Todos ellos se sirven de la puesta en escena como valor intrínseco de la creación poética, y constituyen un núcleo de poetas que sin pertenecer a un movimiento orgánico, marcan una tendencia dominante en la producción poética francesa contemporánea. Tal como señala Jan Baetens, esta "écriture du corps, où le texte sert à faire travailler la matérialité du corps contre l'idéalité du langage, est devenue aujourd'hui une des voies royales de la poésie extrême-contemporaine” (Baetens, 2014: 68). 
Varios son los afluentes que convergen en las corrientes de la interpretación poética. La dramatización de los textos poéticos se nutre de la influencia directa del teatro, por un lado. No por casualidad Artaud es actor dramático y de cine, además de autor. Junto con la puesta en escena, otra de las características que comparten estos poetas es la importancia que se otorga a la dimensión sonora del lenguaje. Las palabras, para todos ellos, no son sólo un soporte para comunicar, sino que otorgan un valor importante a la materia fónica de la que están constituidas. La interpretación poética se vincula de este modo con la interpretación musical. Igualmente, el desarrollo de las técnicas de grabación y manipulación supuso un elemento capital para la concreción y desarrollo de esta práctica poética junto con otras corrientes que también han aportado su influencia a la poesía de la puesta en escena, como son la música concreta y la poesía sonora.

\section{Claves históricas}

El futurismo italiano y el dadaísmo alemán son los dos movimientos literarios que a principios del siglo XX reivindican y ponen en práctica un concepto sonoro de la poesía, situando el acento en el valor estético de la música de las palabras como materia poética.

Los primeros en incidir en la dimensión sonora de las palabras son los futuristas italianos. Poco después, el dadaísmo alemán, compuesto por los artistas que buscan refugio en Zurich durante la Gran Guerra, Hugo Ball, Tristan Tzara, Raoul Hausmann, Schwitters, lleva a cabo las primeras manifestaciones de poesía fonética. Desde un punto de vista teórico a través de escritos y manifiestos, y en la práctica, futuristas y dadaístas reclaman la capacidad expresiva del lenguaje como materia acústica.

Marinetti firma el manifiesto fundacional de futurismo en 1909 y Russolo publica El arte de los ruidos en 1913. Los cuatro manifiestos futuristas van a ser determinantes para la historia de la poesía de vanguardia y la literatura europea: Manifiesto técnico de la literatura futurista (1912), Respuestas a las objeciones (1912), Destrucción de la sintaxis - Imaginación sin hilos - Palabras en libertad (1913) y Esplendor geométrico y mecánico y la sensibilidad numérica (1914). Estos cuatro manifiestos, con otros textos están reunidos en un libro editado exclusivamente en francés en 1919, y que incluye la declaración de principios titulada "Onomatopeyas y Verbalización abstracta", además de fragmentos de su famoso poema "Zang Tumb Tumb” (1914) y otros como "Dunes” que será leído durante la primera sesión en 1916 del también famoso Cabaret Voltaire de Zurich, fundado por Hugo Ball, y en torno al cual se constituye el germen del dadaísmo.

Ya en sus poemas "Prologue" y "Ode" que forman parte de Les Poésies de A.O. Barnabooth (1908) Valéry Larbaud, o Apollinaire en "La Victoire", incluido en Calligrammes (1918), hacen alusión a los ruidos como materia poética, aunque de forma descriptiva y sin llegar a vaciar de su contenido semántico al lenguaje para convertirlo en escueta expresión sonora. Podemos encontrar reproducciones onomatopéyicas de ruidos en Pierre Reverdy y Max Jacob. De manera 
especialmente relevante Vicente Huidobro es de los primeros en explorar las posibilidades expresivas de la dimensión sonora del lenguaje en el Canto VII de Altazor (1931). Reseñables con las experiencias surrealistas, como la interpretación del poema "Suicide" que Philippe Soupault recuerda en 1993 en el documental monográfico que le dedican en 1993 el INA, en colaboración con el Centre Georges Pompidou y la cadena de televisión La Sept / Arte. Lo que distingue a los poetas de la puesta en escena de las experiencia fonéticas de las primeras vanguardias es que sin renunciar a la voluntad de comunicar en términos de contenidos, aportan a la interpretación de sus textos un componente sonoro asociado a la expresividad física del cuerpo en términos dramáticos.

El arte de los ruidos aparece en Milán en 1913. Russolo se sirve de un instrumento de su propia creación llamado Entonaruidos con el que da conciertos en Milán y Génova junto a sus compañeros futuristas, y más tarde en Londres, donde conoce a Stravinski, que se interesa por el entonaruidos y su aplicación en una orquesta común. En El arte de los ruidos habla de ciencia acústica y de las cualidades y calidades de sonido, armonía, de los timbres y ritmos de los ruidos en la naturaleza, de la guerra, o la importancia de las consonantes en el lenguaje en tanto que fuente sonora, inventando una escritura musical propia.

Los experimentos poéticos del futurismo influyen directamente en las obras dadaístas que tienen lugar poco después. El estreno del poema Hugo Ball "Gadgi beri bimba" en el Cabaret Voltaire y "Karawane”, de 1916, así como "K’perioum” de Raoul Hausmann de 1918, tienen su origen en las experiencias futuristas. Sin lugar a dudas el poeta dadaísta que más profundizó y más lejos llegó con sus composiciones materializando lo que va a conocerse como poesía fonética es Kurt Schwitters. En sus poemas las indicaciones sonoras son tan significativas como su plasmación visual en la página.

Con Isidore Isou, de origen rumano como Gherasim Luca, llega a Francia en los años cincuenta el movimiento letrista, al que enseguida se suma el también poeta Gil Jospeh Wolman ${ }^{1}$. El letrismo otorga un protagonismo exclusivo a la letra como receptáculo de valores poéticos y musicales. Enseguida se expande no sólo al ámbito poético sino que cobra una dimensión multidisciplinar que se extiende a la plástica y al cine experimental. Con la poesía y la música concreta y electroacústica, surge en estos mismos años una nueva corriente denominada poesía sonora. Henri Chopin, artista multidisciplinar aunque eminentemente poeta, o Bernard Heidsieck, están vinculados a esta nueva corriente. El desarrollo tecnológico del magnetófono permite grabar la voz directa del poeta, a la vez que su manipulación y mezcla con elementos sonoros externos al propio lenguaje.

A finales de los años setenta un nuevo fenómeno musical nace en los barrios marginales de Nueva York: el Rap (que no significa otra cosa que ritmo y poesía,

\footnotetext{
${ }^{1}$ El MACBA le dedicó una amplia exposición en 2011.
} 
Rhythm and Poetry). Su difusión internacional llegará una década más tarde, originando corrientes musicales y culturales como el Hip-Hop, el Graffiti o el Scracht. En el Rap los textos cobran una importancia que supera la base musical sobre la que son dichos. A la par irrumpe un movimiento poético denominado "Slam" (golpe, portazo), cuya fuente directa es el Rap, estrechamente unido con el que aparecerá una década más tarde bajo el apelativo de Spoken Word (palabra hablada). Ambas corrientes beben de las fuentes del Rap, por un lado, y también del modo en que los poetas beatniks, y en particular Allen Ginsberg, interpretaban sus poemas en directo y sobre todo a través de la radio a principios de los 60. La radio supuso un medio de difusión capital para las nuevas tendencias literarias. Gracias a la radio conservamos la fallida emisión de la grabación de Artaud "Pour en finir avec le jugement de dieu” por la Radiodifusión francesa en 1947. Las propias técnicas de grabación, por otra parte, facilitaban la utilización de sonidos asociados al propio texto poético.

La puesta en escena poética comparte con la poesía fonética de las vanguardias históricas su interés por la dimensión sonora de las palabras, reducida en el caso de futuristas y dadaístas a pura expresión fonética. La palabra se transforma en ocasiones en grito: Pierre Albert-Birot acota su poema La leyenda con la notación de "para gritar", Artaud comienza Pour en finir avec le juegement de dieu con un grito desgarrador. Recordemos también el célebre poema de Ginsberg The Howl. Todos ellos, y en especial Gherasim Luca, empujan el lenguaje hasta los límites del silencio, y entonces la palabra se vuelve imposible para convertirse en grito. Los poetas de la puesta en escena utilizan al igual que la poesía sonora de la incorporación de elementos ajenos a la estricta realización vocal, y con el Slam y el Spoken Word el gusto por la improvisación. Para Artaud y Luca, la interpretación es una parte indisociable de aquello que caracteriza la esencia y el alcance del poema y su dramatización.

El denominador común que sirve de hilo conductor es una práctica poética que no se conforma con "leer" los textos sino que hace hincapié en la "interpretación" del poema, entendiendo por interpretación tanto la atención que el poeta presta al cuerpo sonoro de las palabras como a los elementos puramente dramáticos que intervienen en su realización. De este modo, la puesta en escena forma parte del poema propiamente dicho y se constituye en rasgo de estilo.

\section{Primero fue la voz}

El poema fue dicho antes que impreso y leído. La poesía nace vinculada a la voz como su soporte primigenio: "Longtemps, longtemps —escribe Paul Valéry—, la voix humaine fut base et condition de la littérature. La présence de la voix explique la littérature première" (Valéry, 1960 : 549). "Les qualités que l’on peut énoncer d'une voix humaine - escribe en otro momento- sont les mêmes que l'on doit étudier et donner dans la poésie" (Valéry, 1960 : 350). Esto es, precisamente, una de las características que define la poesía de estos poetas, su voz, la manera 
intransferible de interpretar su poesía. No se trata de "leer" sin más, sino de convertir la dicción y el cuerpo entero del poeta en la expresión de la misma poesía.

En el prólogo a su conocido e influyente poema "Un coup de dés jamais n’abolira le hasard” aparecido en la revista Cosmopolis en 1897, Stéphane Mallarmé apunta la dimensión sonora del poema y de su puesta en escena. Entiende la poesía en términos musicales y establece una equivalencia entre espacio en blanco y silencio en tanto que elementos constitutivos de la medida y el ritmo:

Les «blancs » en effet, assument l'importance, frappent d'abord; la versification en exigea, comme silence alentour, ordinairement, au point qu'un morceau, lyrique ou de peu de pieds, occupe au milieu, le tiers environ du feuillet: je ne transgresse cette mesure, seulement la disperse. Le papier intervient chaque fois qu'une image, d'elle-même, cesse ou rentre, acceptant la succession d'autres et comme il ne s'agit pas, ainsi que toujours, de traits sonores réguliers ou vers - plutôt, de subdivisions prismatiques de l'Idée, l'instant de paraître et que dure leur concours, dans quelque mise en scène spirituelle exacte, c'est à des places variables, près ou loin du fil conducteur latent, en raison de la vraisemblance, que s’impose le texte (Mallarmé, 1992 : 423-424).

Mallarmé entiende que la tipografía y su traducción en términos vocales o interpretativos se comportan de forma equivalente, con modulaciones ascendentes o descendentes a modo de articulación musical. Plantea aspectos teóricos que Artaud poco después pondrá en práctica, y desarrollará más tarde de forma extraordinaria Gherasim Luca.

\section{De la voz al grito}

\subsection{El grito de Pierre Albert-Birot}

Cuando Pierre Albert-Birot escribe su poema "La légende" conoce las realizaciones futuristas de Marinetti. Otros de sus poemas como "Ensayo de poesía pura”, "El avión" reflejan la influencia de las propuestas, teorías y realizaciones del futurismo italiano. Albert-Birot subtitulaba su poema "para gritar y bailar", dejando patente tanto el aspecto teatral del texto, como su pretensión sonora.

"La légende" está en sintonía con el panorama sonoro de la poesía y de la música de su tiempo. La disposición gráfica de los elementos del poema, que persigue una percepción simultánea en la página, sugieren una polifonía visual y musical. Por otra parte, podemos observar el uso fonético que se otorga a las letras, sonidos, ruidos en forma de grafías. Aparecen indicaciones para la interpretación de vocales y consonantes:

éééééééééé

Eééééééééé

(válvula)

LA STATUE

Le fils est depuis longtemps sur la terre

Il a vieilli comme un homme

Aux côtés de Blancheur sa femme 


\section{LA FOULE}

Et voici la mort qui empêche le beau guerrier

De se relever

Ah ---------- (très prolongé) (Albert-Birot, 1987: 164).

"La légende" de Pierre Albert-Birot posee, sin embargo, con respecto a los textos de Marinetti y Schwitters, un fuerte componente narrativo y teatral, como queda dicho de forma explícita en su título y en las acotaciones que encabezan el poema:

Sur scène se dresse une immense statue, aussi haute que possible, six, huit, dix mètres, figurée par un plan découpé, les bras son mobiles, ils se lèvent et s'abaissent au moyen d'un fil pour accompagner les danses, les yeux ajourés s'éclairent au commencement du spectacle et s'éteignent à la fin, lumière blanche quand la statue parle et de différents couleurs quand la foule crie et danse, la bouche énorme est l'orifice d'un grand mégaphone dans lequel l'acteur, dissimulé derrière la statue, récite le poème. La bouche se ferme quand le récit termine. La foule est massée au pied de la statue (Albert-Birot, 1987: 164).

Del poema de Albert-Birot no conocemos realización musical ni puesta en escena, aunque podemos imaginarnos los gruñidos ritmados de la muchedumbre a cada intervención la estatua y sus agitaciones a modo de danzas a los pies del altavoz narrando el viaje a la tierra del hijo del Poeta Padre. Es manifiesto, no obstante, el interés de Pierre Albert-Birot por el teatro y la dimensión narrativa de la poesía, recuperando así su carácter más épico, como lo demuestran los más de cuarenta años que, desde que en 1918 comenzara su escritura, dedicó a su monumental epopeya Grabinoulor. Nos encontramos, junto con los dos poemas citados de Marinetti y Schwitters, ante uno de los textos fundacionales de la poesía fonética.

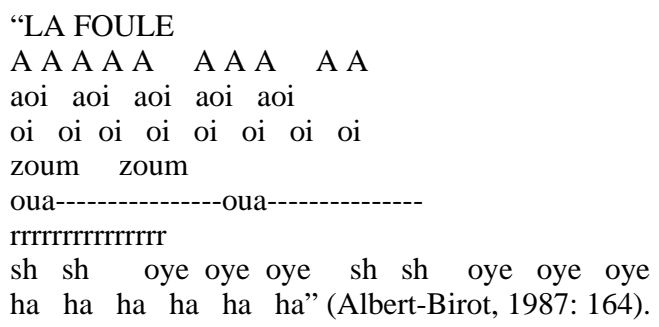

Si bien Pierre Albert-Birot anuncia lo que será la puesta en escena poética, Antonin Artaud es el primero en llevarla a la práctica. Artaud entiende la poesía como manifestación total y no sólo resultado de una expresión escrita de índole literario. La poesía es, por tanto, un estado en donde se encuentran implicados tanto el espíritu como el cuerpo de poeta. El poeta no lee sus textos, se vuelve texto, los sufre y los expresa poniéndolos en escena. 


\subsection{El grito de Antonin Artaud}

En su célebre texto de 1932 "Le théâtre de la cruauté", Artaud evidencia su preocupación por renovar la palabra a través de los elementos dramáticos con el que el teatro contribuye a la expresión poética, un teatro nuevo a través de un lenguaje nuevo emparentado con el lenguaje de los sueños:

Ce que le théâtre peut encore arracher à la parole, ce sont ses possibilité d'expansion hors de mots, des développement dans l'espace, d'action dissociatrice et vibratoire sur la sensibilité. C'est ici qu'interviennent les intonations, la prononciation particulière d'un mot (Artaud, 1964 : 137).

Artaud pretende superar "les impuissances de la parole" (Artaud, 1964 : 146). Se propone conseguirlo a través de una renovación del sentido de las palabras. Artaud quiere ir más allá del significado convencional del lenguaje, una palabra poética que no se conforma con designar aquello que nombra sino que apunta a un nivel espiritual, mágico. Para ello aborda el lenguaje como un todo en donde los elementos de la palabra, su significado, su sonido y los gestos que la misma palabra entraña se alíen para conseguir un resultado que va más allá de la estricta significación. Artaud quiere ir al otro lado de lenguaje en busca de un lenguaje todavía por determinar, un lenguaje "dans l'espace, langage de sons, de cris, de lumières, d'onomatopées” (Artaud, 1964 : 138). Un lenguaje total para una poesía total.

Entre el 22 y el 29 de noviembre de 1947, apenas unos meses antes morir, Antonin Artaud graba en los estudios de la radio francesa "Pour en finir avec le jugement de dieu”, con la colaboración de Maria Casarès, Roger Blin y Paule Thévenin. Su difusión estaba prevista para el 2 de febrero de 1948, pero fue censurada por el director de la Radiodifusión francesa. Unos días más tarde, el 5 y 23 de febrero, tendrán lugar dos audiciones privadas para un reducido grupo de escritores e intelectuales.

"Pour en finir avec le jugement de dieu" es la puesta en práctica de la teoría dramática de Artaud llevada hasta sus últimas consecuencias. Inflexiones de voz, gritos, instrumentos de música, gestualidad fonética se dan cita para componer un cuadro que tiene como objeto impactar de lleno en el espectador. El poema de Artaud sólo puede ser entendido en su plenitud desde la misma interpretación. Al escuchar la grabación nos damos cuenta de inmediato que el propósito del autor va más allá de una simple lectura. Se trata de una puesta en escena en toda regla. Artaud no lee su poema, interpreta un delirio. El contenido del poema, por otra parte, narra una historia de ciencia ficción que el tiempo, como la mayoría de las historias de este género, termina por hacer realidad.

El texto se compone de cinco partes. La primera es interpretada por el mismo Artaud. La segunda, titulada TUTUGURI. LE RITE DU SOLEIL NOIR, presentada como un baile para gritar y bailar, similar a como Pierre Albert-Birot lo hace con LA LEYENDA, la interpreta Maria Cararès. La tercera parte, bajo la nomenclatura LA RECHERCHE DE LA FECALITE, es interpretada por Roger Blin, actor y director de escena. Una cuarta sección corre a cargo de Paule Thévenin, 
amiga y editora tras su muerte de sus obras completas. La quinta y última parte la cierra de nuevo el propio Artaud en una especie de auto entrevista, donde el poeta se interroga y responde a sí mismo interpretando mediante la inflexión de la voz, y en donde cada uno de los personajes se corresponde con los diferentes registros. Se trata en realidad de un monólogo donde intervienen distintos personajes que son el mismo y diverso. Artaud imposta su voz y se debate desdoblándose a lo largo de un diálogo inquietante que por momentos roza el delirio.

Como telón de fondo podemos escuchar gritos, ruidos de percusión y xilófono, gongs, golpes, sonidos vocales a cargo de Artaud y Roger Blin en donde, también a modo de intercambio, dialogan un lenguaje inventado compuesto por cacofonías y glosolalias. La grabación concluye con un opaco y seco redoble de tambor.

El primer párrafo es interpretado por Artaud utilizando cuatro voces diferentes, como si cuatro personajes se dieran cita en un solo cuerpo. La Voz 1 es aguda, estridente, seguida inmediatamente por un descenso en el tono substituida por la Voz 2, una voz grave, solemne, para volver tras un breve inciso con la Voz 1, e introducir la Voz 3, que se sitúa en un nivel estándar de convencionalidad, dando paso a la Voz 4, que reproduce la modulación característica de la arenga militar. A lo largo de todo el texto, Artaud recurre a estos cuatro registros para crear una polifonía que resuena en el interior de un personaje único.

En la última parte titulada CONCLUSIONS y que lee de nuevo Artaud, el autor dialoga consigo mismo. En este momento Artaud interpreta diferentes voces que lo interrogan atribuyéndoles igualmente a cada una de ellas un registro en particular. A las preguntas de ese tribunal el poeta va respondiendo pausadamente, y en cada una de las respuestas aparecen de nuevo las voces de las diversas identidades que habitan en el interior del personaje Artaud.

Las cinco partes están encabezadas por un aforismo en forma de poema y a ambos lados del poema aparecen un conjunto de glosolalias, un lenguaje hermético inventado por el propio Artaud con el objeto de que esos sonidos sean interpretados $\mathrm{y}$, desde un punto de vista sonoro, comuniquen un significado por otra parte indescifrable. Se trata de una escritura de signos concebidos para ser articulados de modo que su propia naturaleza fonética constituya una fuente de significado traducido en sensaciones o impresiones no muy lejos a las que podemos encontrar en poemas dadaístas y futuristas, o las grafías fonéticas de Albert-Birot.

Jacques Derrida interpreta las glosolalias de Artaud como su propuesta de un lenguaje universal liberado de las convenciones de la significación. En el transfondo de ese lenguaje reposa la idea de la crueldad como principio creativo propuesto por el autor en su "Théâtre de la cruauté":

Ayant toujours préféré le cri à l'écrit, Artaud veut maintenant élaborer une rigoureuse écriture du cri, et un système codifié des onomatopées, des expressions et des gestes, une véritable pasigraphie théâtrale portant au-delà des langages empiriques, une grammaire universelle de la cruauté (Derrida, 1967 : 287).

Este nuevo lenguaje expresado mediante sonidos transcritos y un sistema propio de notación, se repite en múltiples momentos en sus últimos escritos. En última 
instancia Artaud pretende inventar un nuevo dios con su propio lenguaje divino, un lenguaje perfecto, libre de ataduras semánticas, de limitaciones, donde, como dirá más tarde Christophe Tarkos, el signo es liberado de su sentido y se convierte en lenguaje puro, en pura significación.

Artaud concibe un lenguaje total emparentado directamente con la interpretación musical y elementos harmónicos y rítmicos que aportan al texto tanto significado como materia sonora. Artaud hace de la puesta en escena el elemento fundamental de significación del que no puede ser disociado. Cuando Artaud afirma que ese teatro nuevo "pousse la voix. Il utilise des vibrations et des qualités de voix. Il fait piétiner éperdument des rythmes. Il pilone des sons" (Derrida, 1967: 140) pone el acento en la dimensión física de la palabra como depositaria de sentido.

Para Artaud la palabra no puede ser disociada de su realización físico-corporal. Palabra y cuerpo forman parte de una misma unidad comunicativa: "de plus la nécessité d'agir directement et profondément sur la sensibilité par les organes invite, du point de vue sonore, à rechercher des qualités et des vibrations de sons absolument inacoutumées". Se trata, en última instancia, de "produire des sons ou des bruits insuportables, lancinants”, añade (Derrida, 1967 : 147), entendiendo por insoportable no tanto su volumen sino su dimensión espiritual y psicológica.

\subsection{Del grito al balbuceo de Gherasim Luca}

En su Abecedario el filósofo Gilles Deleuze calificaba a Gherasim Luca, junto a Charles Péguy y Louis-Ferdinand Céline, como uno de los grandes estilistas de la literatura francesa. Según Deleuze, Luca consigue su marca de estilo a través de dos procedimientos: forzar la sintaxis y hacer tartamudear la lengua. Efectivamente, la poesía de Gherasim Luca es un sistema lingüístico en desequilibrio. Asistimos a una especie de regresión verbal en donde el poeta sale en busca de un lenguaje primero, infantil, torpe, como si de un niño aprendiendo a caminar se tratara y en sus primeros pasos tambaleantes consiguiera a duras penas mantenerse en equilibrio ante la mirada expectante y la respiración suspendida de quienes lo observan al límite de la caída. Lo que Deleuze no explica es que el efecto sonoro de ese tartamudeo, de ese desequilibrio sintáctico, no lo consigue Luca mediante la escritura propiamente dicha, sino gracias a la interpretación de esa escritura. La poesía de Gherasim Luca no puede entenderse sin su voz y su manera intransferible de decir, que se convierten en su marca reconocible. Su manera de decir es propiamente su estilo.

Gherasim Luca no lee sus poemas, los interpreta. La dicción misma forma parte del sentido y de la forma de aquello que desde un punto de vista literario está ocurriendo en escena. Porque se trata de eso, de una puesta en escena sonora y gestual. Luca y su manera de interpretarse son indisolubles. Interpreta sus poemas como se interpreta una música, es consustancial a la materia poética que les hace ser lo que son. La poesía de Luca es el modo en que la voz del poeta da sentido a la compleja, y en ocasiones angustiosa, articulación y desarticulación de una sintaxis 
poética que se dice al tiempo que se desdice. Construir y deconstruir son en este caso sinónimos.

Raoul Sangla realiza una austera filmación de las realizaciones de Luca, que interpreta y gesticula una angustiosa cascada de versos. Habla una lengua desconocida, que surge de una oscuridad primera. Sus palabras son las de un herido por la palabra al que le cuesta trabajo respirar, y toma aliento a duras penas para seguir adelante. Habla en un equilibrio inestable, dudoso, imposible casi. Gherasim Luca escribe como si estuviera aprendiendo a hablar, como si esas palabras se estuvieran pronunciando por vez primera. Asistimos al nacimiento de un lenguaje nuevo, haciendo realidad el sueño de Artaud, haciendo significar al lenguaje de una manera propia, primera, exclusiva, desconcertante.

El edificio poético de Luca está concebido como un mecano en donde las piezas se van uniendo hasta construir una gran estructura a modo de tela de araña gestual y sonora. La sucesión de estas piezas del mecano obedece a una combinatoria que avanza a saltos, dejando atrás fragmentos para incorporar elementos nuevos que hacen variar de sentido y de significado el discurso a medida que avanza. En su progresión combinatoria la estructura de poema es objeto de pequeñas mutaciones dentro de un ritmo continuo y aparentemente circular. Algunas de las piezas desaparecen para incorporar un nuevo detalle que permite una nueva permutación. El resultado final consiste en un rompecabezas sonoro en el que las palabras se desmenuzan originando nuevas palabras que vuelven a diluirse en la corriente musical del poema.

A partir de una pieza que sirve de raíz se van sumando otras piezas hasta articular una estructura sobre la base primera que crece y se complica en torno a una misma base semántica y fonética mediante una sucesión de aliteraciones. En "Héros-limite" la construcción del mecano poético se genera a partir del elemento /mor/ en tanto que pieza polisémicas y cambiante:

La mort, la mor folle, la morphologie de la méta, de la métamort, de la métamorphose ou la vie, la vie vit, la vie-vice, la vivisection de la vie (Luca, 1987 : 15).

El poema crece y avanza sobre sonidos que van solapándose y haciendo que, desde un punto de vista sonoro, el discurrir tenga lugar de manera coherente, mientras que la parte semántica actúa de contrapunto. Al núcleo inicial /mor/ se le suma la pieza fonética /fol/ para ver suplicada inmediatamente cambiando así su significado en /fologi/

El poema se articula gracias a una adición de elementos fonéticos que transforman a su vez su significado. Pero lo que despierta nuestra curiosidad, si prestamos atención al modo en que Gherasim Luca interpreta su texto, es que la progresión fonético-semántica del texto se fundamente en una cuidada utilización de las sílabas cortas y largas. En el primer tiempo de este primer movimiento son las sílabas largas las que catapultan el poema hacia delante haciendo coincidir progresión semántica y duración.

/de la me ta/ 
/de la me ta mor/

/de la me ta mor foz/

El efecto sonoro de tartamudeo característico en la interpretación de Luca no es otra cosa que la combinación de sílabas breves y largas, y en donde la progresión tanto semántica como sonora del poema se fundamenta en la utilización de la sílaba larga a modo de trampolín que permite catapultar el discurso hacia delante.

En otro de sus poemas titulado "Zéro coup de feu" prepara el inicio de la construcción a partir de un sujeto "Tes chaussures" y un verbo "glisser". Estos dos elementos actúan de articulación sobre que la que se expande la serie de permutaciones que forman el conjunto del poema. Inmediatamente después el complemento "le mot de passe" va a reaparecer en el tercer verso y se elimina para volver en el verso quince, como si la evolución del poema volviera atrás para catapultarse en un intento de seguir adelante.

Tes chaussures glissent le mot de passe

sous le palais de ma bouche

Ma langue suce le mot de passe

Sous le palais de ta bouche

ma langue glisse (Luca, 1991: 41).

$\mathrm{La}$ "s" sorda es el sonido dominante y ayuda a estructurar el poema en su totalidad. Las demás variantes van multiplicando las distintas realizaciones sonoras a modo de polifonía verbal. El circustancial "sous le palais de ma bouche" desempeña una función de bajo continuo y permite de este modo a la melodía desarrollarse sobre una apoyatura que se repite como frase principal:

\author{
Tes chaussures glissent dans l'aile droite \\ sous le palais de ma bouche \\ Tes chaussures glissent dans l'aile gauche \\ Ta chaussure droite sous le palais de ma bouche \\ Ta chaussure gauche dans l'aile droite (Luca, 1991: 41).
}

El sujeto "Tes chaussures" y el verbo "glisser" funcionan como piezas fundamentales en torno a las cuales se organiza el poema y su desarrollo, con un contrapunto al comienzo del poema mediante la permutación de la vocal anterior /i/, y del verbo "glisser" por el sonido de la vocal redondeada anterior /y/ del verbo "sucer". Más adelante la combinatoria fonética de la /s/ sorda se presenta como un bucle que introduce la reaparición de complemento inicial "le mot de passe" cerrando así la progresión en un círculo inacabable:

Ma langue glisse dans ta chaussure droite

Ma langue chausse ta chaussure gauche

Sous le palais de ma bouche

tes chaussures chaussent ma langue

Ta langue suce le mot de passe

Dans ta chaussure gauche ma langue glisse

Sous le palais de ma bouche ta chaussure droite (Luca, 1991: 41). 
En el poema los versos "tes chaussures chaussent ma langue" cumplen la misma voluntad permutativa y modifican su ordenamiento transformándose en "Ma langue chausse ta chaussure droite" incorporando una pequeña pieza al mecano que ofrece la impresión de redireccionar el sentido del poema.

Tal como Mallarmé lo concibió y puso en práctica por vez primera en el ya citado e influyente "Un coup de dés jamais n’abolira le hasard", los silencios desempeñan un papel decisivo en los poemas de Luca, silencios vocales y silencios gráficos. Vocales, en los intervalos que Ghérasim Luca imprime entre las palabras, entre secuencias. Gráficos también en el modo en que el poeta sangra sus textos y esparce las palabras y los versos sobre la página a modo de partitura, en donde una palabra ocupa todo el espacio gráfico destacando en el centro del silencio de la página. Lo que hace que la obra de Ghérasime Luca resulte irrepetible no son tanto las figuras retóricas y los recursos formales, sino su exclusiva manera de interpretar esos poemas por el mismo autor. Como señalábamos más arriba, los poemas de Ghérasim Luca no se entienden sin la interpretación de Ghérasim Luca. El uso de aliteraciones y paranomasias, el modo en el que arrastra las erres, su tartamudeo característico, los susurros, las repeticiones obsesivas cobran sentido cuando son interpretados con la voz y el cuerpo del poeta materializando ese lenguaje nuevo y total con el que soñaba Antonin Artaud.

\section{A modo de conclusión}

Y al final de la palabra no hay el silencio, está el grito. Cuando nos quedamos sin voz, cuando ya no es posible nombrar ni decir, la palabra se desgarra y se vuelve dolor. Pierre Albert-Birot transcribió con signos las formas del grito. No sabemos si en algún momento interpretó su "Légende", pero quedó constancia escrita de las palabras, cuando se desmoronan como un castillo de arena y aparece su esqueleto, el poeta pone ante el lector-auditor la parte más básica de lenguaje. Cuando nos faltan las palabras, porque todavía no hemos aprendido a nombrar las cosas, porque hay un dolor desproporcionado que las suspende, nuestra voz se transforma en grito. Lo primero que escuchamos en Pour en finir avec le jugement de dieu es el grito de un hombre que no soporta el dolor. Luego se interroga, responde, pregunta de nuevo, inquiere. Pero primero grita desesperadamente.

El grito es el reverso de la palabra, el lenguaje sin domesticar, la expresión más desnuda y desprovista a la que llega el poeta tras haberlo intentado todo. Más allá del silencio está la voz, y al borde del abismo de la palabra irrumpe el grito para precipitarse de nuevo en el silencio. Un palíndromo poético que gira en mitad de la noche consumido por el fuego. Gherasim Luca empuja la expresión poética hasta los límites de la palabra. Camina tambaleante, parece que vaya a derrumbarse, duda, se adelanta unos cuantos pasos inseguros, comienza de nuevo y se le caen de las manos las palabras, las sostiene y caen de nuevo en un intento desesperado por decirnos algo mediante un lenguaje primitivo, tal vez primigenio, el de un niño que 
aprende a hablar, que descubre las palabras, como si Gherasim Luca escribiera por primera vez el primer poema del mundo.

Los poemas de Artaud y Ghérasim Luca, así como de los poetas que hoy en Francia hacen de la interpretación y puesta en escena un rasgo constitutivo de la poesía, privados de la voz de sus autores, pierden una parte esencial de su forma. No es posible entenderlos plenamente. La lectura moderna, en solitario y en silencio, que nace con la imprenta y el abandono de la tradición oral y la improvisación, para la poesía y para la música, carece de sentido para esta literatura, que alcanza su plenitud en la realización sonora del lenguaje, transformado en música. Y la destilación de esa música desemboca en el grito. El camino iniciado por Artaud y Gherasim Luca cuenta con seguidores e intérpretes que han convertido la puesta en escena poética en rasgo determinante. La banalidad de libros como Chaussures o Tomates de Nathalie Quintane cobra una nueva dimensión gracias a su manera de decir esos textos y ponerlos en escena con similar banalidad: la autora sentada en un jardín y recibiendo tomates que atrapa, guarda, pela con un cuchillo al tiempo que escuchamos la voz en off de la autora diciendo el poema. Otro tanto sucede con el poema "Un jour" de Charles Pennequin. Escuchar al autor interpretar su poema nada tiene que ver con leer el texto, pues el estilo de Charles Pennequin es Charles Pennequin leyendo su poema "Un jour". El más relevante de todos ellos ha sido sin duda el poeta ya desaparecido Christophe Tarkos. Nada tiene que ver leer a Tarkos que oír a Tarkos. Sólo escuchándolo y viéndolo es posible entender la tragicomedia que trata de dar una explicación al dolor de la palabra y de la vida. Su sentido del humor, su descarada manera de interpretar, sus pequeñas y aparentemente inocentes maneras de provocar son formas de supervivencia. Su honestidad y los resultados literarios que alcanzó lo convierten en uno de los poetas de referencia de la segunda mitad del siglo XX.

Artaud y Luca, y también Pierre Albert-Birot si bien no conservamos testimonios sonoros, constituyen tres referencias clave en esta cadena de poetasintérpretes que va a eclosionar a finales del siglo XX y de la que tenemos constancia gracias a los medios de grabación y difusión que hacen posible que hoy esta nueva forma de tradición oral se conserve y se perpetúe.

\section{REFERENCIAS BIBLIOGRAFICAS}

Albert-Birot, P., (1987) Poésie 1916-1920. Trente et un poèmes de poch., Poèmes quotidiens. La joie des sept couleurs. La triloterie. Mortemart, Rougerie.

Ginsberg A., (2004) The Allen Ginsberg Audio Collection. New York, Harper Collins Publischers.

Ansón, A., (2012) El ruido y la lira. Poetas franceses performers. Zaragoza, Eclipsados. Baetens, J., (2014) Pour en finir avec la poésie dite minimaliste. Bruxelles, Les Impressions Nouvelles.

Artaud, A., (1964) Le Théâtre et son double. Paris, Gallimard (Coll. Idées).

Artaud, A., (1974) Euvres complètes. XIII : Van Gogh, le suicidé de la société. Pour en finir avec le jugement de dieu. Le Théâtre de la cruauté. Lettres à propos de Pour en finir avec le jugement de dieu. Paris, Gallimard. 
Bobillot, J-P., (1996) Heidsieck poésie action. Paris, Jean Michel Place Broutin, G-P, Courtay, J-P., Gillard, J-P. \& F. Poyet, (1972) Lettrisme et hypergraphie. Paris, Editions Georges Fall (Coll. BibliOpus).

Chopin, H., (1979) Poésie sonore internationale. Paris, Jean-Michel Place.

Chopin, H., (2004) Le Grand Monde la grande poésie. Paris, Le Corrideur Bleu.

Deleuze, G., (2004) L’Abécédaire de Gilles Deleuze. Paris, Editions Montparnasse.

Deleuze, G. \& C. Parnet, (1977) Dialogues. Paris, Flammarion.

Derrida, J., (1967) L'Ecriture et la différence. Paris, Seuil.

Heidsieck, B., (1999) Respirations et brèves rencontres. Marseille, Éditions Al Dante (Coll. Niok)

Hulten, P., (1986) Futurismo \& Futurismi. Milano, Bompiani.

Luca, G., (1987) Héros-limite. Paris, José Corti.

Luca, G., (1991) La Proie s’ombre. Paris, José Corti.

Luca, G., (2001) Ghérasim Luca par Ghérasim Luca. Paris, José Corti.

Luca, G., (2008) Comment s'en sortir sans sortir. Paris, José Corti.

Mallarmé, S., (1992) Euvres (textes établis avec chronologie, introduction, notes, choix de variantes et bibliographie par Yves-Alain Favre). Paris, Bordas (Coll. Classiques Garnier).

Orlandi, S., (2014) "Gherasim Luca, Paul Celan : un au-delà de la langue dans la langue ?” in Trans. Revue de littérature générale et comaprée [En línea]. № 17, disponible en : http://trans.revues.org/890 [Último acceso el 8 de febrero de 2015].

Pennequin, Ch. [jeanpaulhirsch], (2010, el 10 de marzo) "Un jour” [archivo de vídeo]. Disponible en: https://www.youtube.com/watch?v=-9aRcJo4iN4\&feature=related [Último acceso el 8 de febrero de 2015].

Prigent, Ch., (2000) Salut les anciens salut les modernes. Paris. P.O.L.

Prudon, M. (dir.), (2001) Les avant-gardes et la musique?. Saint-Denis, Université Paris 8 Vincennes Saint-Denis.

Quintane, N. [POLEditeur] (2010.el 3 de octubre) “Tomates” [archivo de vídeo]. Disponible en https://www.youtube.com/watch?v=ZG90AcLbS8Y [Último acceso el 8 de febrero de 2015].

Raileanu, P., (2004) Les étrangers de Paris. Ghérasime Luca. Paris, Oxus.

Rodríguez, J. C., (1994) La poesía, la música y el silencio (de Mallarmé a Wittgenstein). Sevilla, Renacimiento.

Russolo, L., (1998) El arte de los ruidos. Cuenca, Radio Fontana Mix.

Sarmiento, J. A., (1991) La poesía fonética. Futurismo / Dada. Madrid, Libertarias.

Schwitters. K., (2001) Poesía fonética (Edición de José Antonio Sarmiento). Cuenca, Ediciones de la Universidad de Castilla-La Mancha.

Tarkos, Ch., (2002) Expressif, le petit bidon. Hérouville-Saint-Clair, Éditions Cactus. Toma, J., (2012) Gherasim Luca ou l'intransigeante passion d'être. Paris, Honoré Champion.

Tomiche, A., (2003) "Glossolalies: du scaré au poétique” in Revue de littérature comparée. Gevève, Klincksieck, nº 305, pp. 61.72. 